\title{
A POPULARIZAÇÃO DO CELULAR E AS NOVAS PRÁTICAS SOCIAIS
}

\author{
The popularization of mobile phone and new social practice
}

\author{
Leonilda Adelino António Sanveca Muatiacale
}

Mestre em Comunicação e Semiótica pela Pontifícia Universidade Católica de São Paulo (PUC-SP), Docente e Pesquisadora da Escola de

Comunicaçãoe Artes daUniversidadeEduardoMondlane em Maputo,Moçambique,SãoPaulo,SP-Brasil,e-mail:leosanveca@hotmail.com

\begin{abstract}
Resumo
A posse e a utilização de dispositivos digitais, sobretudo do celular, por um número cada vez maior de moçambicanos constitui-se numa alternativa à mídia tradicional hegemônica. Através desses meios, os indivíduos têm acesso a informações de seu interesse, podem expor seus pontos de vista, e, ao mesmo tempo, têm a possibilidade de veicular suas próprias versões sobre os acontecimentos. Este artigo discute o fenômeno da popularização do celular em Moçambique e analisa as reconfigurações das práticas sociais contemporâneas e sua contribuição para a constituição de novo sujeito social. Nesse cenário, interessa-nos compreender como a apropriação desses dispositivos digitais altera a dinâmica do relacionamento interpessoal e o ritmo de vida das pessoas, sobretudo, das comunidades rurais e periféricas. Esta discussão tem como fundamentação teórica os postulados de Eugênio Trivinho (2007) e Willes Geaquinto (2002) que dissecam, respectivamente, sobre a reconfiguração social e a necessidade de participação efetiva dos cidadãos nesses processos em vista à sua emancipação na definição dos destinos comuns.
\end{abstract}

Palavras-chave: Comunicação. Práticas sociais. Sujeito social. Moçambique.

\begin{abstract}
The possession and use of digital devices, especially mobile phone, for an increasing number of Mozambicans constitutes an alternative to traditional media hegemony. Through these means, people have access to information of interest, can expose their views, and at the same time, they are able to convey their own versions of events. This article discusses the phenomenon of the popularization of mobile phone in Mozambique and examines the reconfiguration of contemporary social practices and their contribution to the establishment of new social subject. In this scenario we are interested in understanding how the ownership
\end{abstract}


of these digital devices change the dynamics of interpersonal relationships and the pace of life, especially in rural communities and remote regions. This discussion has the theoretical postulates of Eugênio Trivinho (2007) and Willes Geaquinto (2002) dissecting respectively on the social reconfiguration and the need for effective participation of citizens in these processes with a view to their emancipation in the definition of common destinations.

Keywords: Communication. Social practices. Social subject. Mozambique.

\section{INTRODUÇÃO}

Não há dúvida de que os meios de comunicação modernos e sua convergência estão reconfigurando as práticas sociais na atualidade. Assistimos a uma transformação rápida da sociedade que cada vez mais é mediatizada; os meios de comunicação tradicionais passam por reconfigurações; aumenta o número de opções de mídias e veículos e a maneira como todos esses meios se imbricam traz um impacto nas relações sociais e na relação dos indivíduos com os dispositivos de comunicação e informação. Mapear este novo panorama e pensar nas possibilidades de inclusão das maiorias excluídas desse processo é, atualmente, um dos grandes desafios de pesquisadores, dos governos locais e de profissionais da comunicação não só de Moçambique como também de outros países considerados periféricos ou em vias de desenvolvimento.

Com a adoção de tecnologias de comunicação e informação cada vez mais velozes é inevitável a ocorrência de algumas mudanças tanto na maneira de apropriação de novos aparatos tecnológicos quanto nas relações sociais porque se abrem inúmeras possibilidades de interação entre os sujeitos interlocutores dos discursos. Por isso, discutir a popularização do celular e suas contribuições na geração de novos processos comunicativos implica refletir também sobre as mudanças no modus vivendi das pessoas que habitam o meio rural e antes não tinham acesso a nenhum tipo de meio moderno de comunicação, salvo o rádio. Mesmo assim, em alguns casos, o sinal de recepção lhes chega ainda com certas deficiências em termos de qualidade de transmissão e seu alcance territorial.

Por um lado, este artigo busca compreender as multifacetadas dinâmicas das práticas sociais contemporâneas mediadas pelas tecnologias de informação e comunicação, neste caso, pelo celular. Este dispositivo apresenta vantagens como a mobilidade, a praticidade, a velocidade na comunicação, maior controle nos gastos, entre outras funcionalidades. Por outro, tem a pretensão de trazer ao debate acadêmico os desafios que se afiguram na sociedade moçambicana em relação ao fluxo de conteúdos simbólicos difundidos pela telefonia móvel. Sem dúvida, há necessidade de se estudar a possibilidade de divulgação de saberes não somente universais, mas também locais, que trazem contribuições válidas para as culturas locais e que podem ser partilhados globalmente.

Como fazer com que os saberes locais moçambicanos encontrem espaço na rede mundial de telefonia móvel, da internet e de outras mídias para que sejam conhecidos e valorizados tanto no contex to local quanto global? É sobre essa temática que nos propomos discutir a seguir.

\section{Comunicação e novas práticas sociais na atualidade}

Não é preciso ser grande especialista da história de Moçambique para perceber as mudanças que o país tem experimentado, sobretudo em relação ao cenário dos meios de comunicação e seu processo de evolução desde a introdução da rádio, dos jornais impressos, no período colonial e às primeiras experiências de televisão no período pós-independência; à entrada da rede de Internet em 1996; da rede de telefonia móvel entre 1997-1998, a qual mudou a dinâmica do cotidiano de parte da população que tem acesso a esses aparatos tecnológicos.

Para compreendermos o cenário atual que se desenha em Moçambique, partimos do conceito de comunicação na ótica de Rodrigues (1994, p. 22), de que "a comunicação não é um produto, mas um processo de troca simbólica generalizada, processo de que se alimenta a sociabilidade, que gera os laços sociais que estabelecemos com o meio ambiente". 
Por tratar-se de um processo de trocas simbólicas, essa definição pressupõe a existência de sujeitos interlocutores que estão inseridos em um determinado contexto no qual produzem e compartilham discursos (mensagens). É nesse sentido que o objeto da nossa pesquisa são as práticas sociais no contexto das mídias digitais, sobretudo o celular enquanto meio de comunicação em Moçambique.

Através da análise dos três elementos principais do processo comunicacional (sujeitos interlocutores, discurso e contexto), propomo-nos discutir também sobre questões ligadas à cidadania e participação da vida social como um aspecto importante que pode ajudar na integração dos indivíduos no ambiente em que estão inseridos. Pela participação na definição da vida social, os indivíduos podem contribuir não só nas mudanças relativas ao comportamento como também na tomada de decisões sobre temáticas da vida comum.

O processo comunicacional é amplo e dinâmico. Através desse processo ocorre o fluxo contínuo de trocas simbólicas entre os sujeitos participantes, por isso, a comunicação acontece em qualquer lugar, em qualquer momento da vida do indivíduo, da comunidade, da sociedade.

Uma maneira (intuitiva e não definidora) de referir-se à intenção comunicacional é considerar que se trata de processos simbólicos e práticos que, organizando trocas entre os seres humanos, viabilizam as diversas ações e objetivos em que se vêem engajados (por exemplo, de área política, educacional, econômica, criativa, ou estética e toda e qualqueratuação que solicita co-participação (BRAGA; CALAZANS, 2001, p. 16).

$\mathrm{Na}$ comunicação há que distinguir duas dimensões importantes. A primeira, é que o processo comunicacional em si é espontâneo e brota da necessidade do ser humano de se comunicar, de se inserir e de interagir com os outros em vários espaços significativos da sua vida como nos grupos de convivência, por exemplo, na família, no bairro, na escola, no trabalho, etc. Nesse sentido, a comunicação permeia as diversas áreas de conhecimento formando interfaces com elas como é o caso da interface com a educação.

É graças a esse caráter espontâneo do processo comunicacional que o indivíduo pode se educar por meio de diversas formas de comunicação, principalmente através da interação com a sociedade.
A segunda dimensão é a de a comunicação existir enquanto sistema organizado de meios de comunicação de massa, que é estruturado em forma de instituições especializadas em produzir, reproduzir e difundir mensagens através dos diversos tipos de veículos e que têm objetivos e metas a atingir num mercado cada vez mais competitivo.

Vistos como um sistema organizado, os meios de comunicação funcionam como intermediários técnicos nas relações sociais, isto é, fazem um papel de mediação entre o meio social e os indivíduos e/ou grupos.

No processo de mediação, as informações que chegam ao público já são antes bem "trabalhadas", editadas de acordo com o ideário e intenções daqueles que estão à frente desses meios como proprietários, profissionais, etc., além de esferas políticas e econômicas detentoras de algum poder na sociedade.

É nesse ambiente, marcado pelo desenvolvimento das tecnologias, que as pessoas passam a sua maior parte do tempo em contato direto com os meios de comunicação de massa: televisão, internet, livros, jornais, revistas, rádio, cinema, etc. No caso de Moçambique, com a entrada da telefonia móvel, o celular tornou-se muito popular porque grande parte da população usa-o para se comunicar.

O que nos instiga nesse panorama é a forma como o celular é apropriado pelos indivíduos, independentemente de estarem em ambientes com rede. Essa nova tendência sugerenos uma investigação mais profunda sobre as transformações em curso. Tais mudanças levantam questões, tanto no que diz respeito à produção quanto à recepção de conteúdos simbólicos.

A apropriação de qualquer dispositivo tecnológico deve ser assumida numa perspectiva crítica e consciente por parte dos usuários e não só como também dos próprios governos locais, de forma a possibilitar um conhecimento mais amplo das vantagens e desvantagens, além das implicações inerentes ao seu uso.

O fenômeno da popularização do celular em Moçambique e sua adoção por grande parte da população rural é uma experiência marcante na história dos meios de comunicação social no país. Nessa ótica, somos levados a pensar na importância da comunicação comunitária como estratégia de educação à cidadania. 
Na comunicação através do celular rompese a distância física, geográfica. Através desses veículos de comunicação, os interlocutores entram em contato em tempo real. ${ }^{1}$ Essa experiência modifica a sua maneira de estar no mundo e de perceber os acontecimentos e as próprias relações sociais. Os indivíduos tornam-se produtores de conteúdos, sobretudo trocam saberes locais que têm a ver com seus ambientes de convivência.

Tomados isoladamente e mesmo em estado de convergência com outros veículos, o celular e a internet são dispositivos carregados de significações culturais cujos textos produzidos e transmitidos em rede só são compreensíveis no contexto em que os usuários estão inseridos. É por essa razão que nos propomos tomar especial atenção para o fenômeno da popularização e apropriação massiva do celular por todas as classes sociais moçambicanas.

Como o celular influencia o cotidiano das relações sociais? $\mathrm{O}$ que motiva um indivíduo a adquirir celular mesmo sabendo que onde vive não há rede e não vai usar o aparelho com frequência até que se desloque para regiões onde haja rede de transmissão? Em outros casos, o indivíduo compra celular, mas não possui domínio de seu funcionamento?

Encontramos algumas possíveis respostas para essas questões como: o estado permanente de ansiedade de informação; a facilidade de comunicação interpessoal; a busca de status e autoafirmação e demonstração de poder aquisitivo e o receio de estar fora da moda. Em suma, esse comportamento revela o desejo de ser visível, de estar presente, de ser reconhecido pelos outros, sobretudo, pelos que fazem parte do círculo de convivência diária (família, amigos, conhecidos, colegas de trabalho).

Podemos compreender essa nova dinâmica de interação social entre os sujeitos à luz do conceito de visibilidade, tecido por Trivinho (2007, p. 72) para quem visibilidade não se reduz à dimensão do que é literalmente visível-audível.

Muito, além disso, diz respeito à propriedade que a produção cultural mediática como um todo tende, se faz diurna e imponentemente presente não só aos sentidos percepcionais (em especial, aos mais socialmente saturados, como a visão e a audição), mas também à mentalidade e às emoções de milhões de cidadãos do mundo inteiro. Visibilidade mediática é tudo aquilo que comparece na cena, na sociedade como algo posto, sentido. A produção de sentido só é possível na relação de partilha.

A questão fundamental talvez seja esta de que se trata de uma nova postura de estar no mundo contemporâneo e de se identificar com os outros e de fazer parte de uma comunidade, de um grupo e de uma sociedade com a qual o indivíduo se identifica. Mas nem sempre essa postura é tomada livremente. No panorama da cultura mediática, alguns processos se desenrolam de forma violenta, é o que Trivinho designa violência simbólica, ${ }^{2}$ uma característica que marca o ambiente da cultura mediática. É violência simbólica no sentido de que há bombardeamento constante de signos pela rede, o que pode levar os indivíduos a ficarem em permanente estado de tensão e consequentemente perder o senso crítico sobre os discursos midiáticos.

Outro aspecto, que podemos considerar como violência simbólica, está ligado aos desequilíbrios na geração e divulgação de conteúdos simbólicos na rede mundial de internet. Percebemos que os saberes locais de países periféricos como Moçambique não tem espaço na rede? O que se vê é que os países mais desenvolvidos têm capacidade de produzir e colocar na rede seus conteúdos diversos, dando continuidade a uma relação hegemônica que não possibilita intercâmbio cultural entre os povos nos diversos campos do conhecimento.

Visto sob este prisma, as mídias digitais são dispositivos tecnológicos que se inserem na vida cotidiana dos indivíduos e pouco a pouco podem substituir, embora não totalmente, os meios tradicionais de socialização como a conversa em volta da fogueira, por exemplo, nas quais as relações interpessoais são valorizadas e a interação é presencial, ou seja, face a face. É nessa ótica que Wurman (1991, p. 94) sustenta a ideia de que "a sociedade de informação com sua ênfase na comunicação eletrônica e no computador transformou as relações humanas em mercadoria."

\footnotetext{
1 Tempo real dialógico, multipolar-bidirecional, flexível (seja live, seja online, com abertura para a participação dos receptores, ou melhor, para a interação tecnologicamente mediada entre alteridades humanas) (TRIVINHO, 2007, p. 255).

2 Violência simbólica (técnica, sutil/sofisticada, invisível/obliterada, transpolítica, estrutural-ciberspacial).
} 
Para que os usuários de celular não caiam nessa lógica mercadológica precisam conhecer amplamente todos os aspectos envolvidos nos processos comunicativos e nos conteúdos construídos e transmitidos tanto na rede de celular como em outros veículos de comunicação de massa. É interessante frisar o papel da publicidade que é veiculada através da rede de telefonia móvel que, muitas vezes, associa a venda de pacotes de produtos, serviços e tarifas à valorização de aspectos identitários, da unidade nacional e, sobretudo, do estar juntos. Essa estratégia discursiva pode persuadir e convencer as pessoas à compra. Podemos ver isso patente na publicidade por celular, outdoor, portais das operadoras mCel e Vodacom, respectivamente ${ }^{3}$ :

“juntos tudo é mais fácil. Contratos Olá com melhores preços e vantagens".

“juntos falamos sem parar. Olá 500, com 500 minutos, 500 sms's grátis”

"juntos falamos sem contar os minutos. Poupa com a tarifa mais baixa do pré-pago no giro de 600."

"Vodacom, aproximando pessoas"

"O melhor do tudobom"

"Tudo com desconto de 20\%"

"Tudo bom na rede com a melhor qualidade" "bom no roaming".

Nessas peças publicitárias estão presentes os objetivos de venda das operadoras, mas essa intencionalidade fica imersa nas mensagens por vir associada aos valores já mencionados anteriormente. Os consumidores distraídos podem se deixar levar mais pelo apelo identitário acabando por comprar os serviços sem refletir primeiro nas vantagens $\mathrm{e}$ desvantagens para avaliarem e decidir melhor sobre o que comprar.
Com a presença e popularização do celular, o processo de difusão e de acesso aos conteúdos simbólicos dá um salto significativo em relação aos meios tradicionais.

Em Moçambique, o aumento de usuários de celular trouxe vantagens para o público, uma vez que possibilita a discussão de assuntos que na mídia hegemônica não são apresentados ou não tem cobertura nacional ${ }^{4}$. Trata-se de uma agenda paralela à agenda midiática e, ao mesmo tempo, nesses espaços se repercutem os temas difundidos também pela mídia hegemônica. Na rede de celular, essa atividade é a mais comum e familiar à maioria das pessoas. Não raras vezes, de forma breve, criticam-se atitudes, postura ou discurso de autoridades políticas ou figuras públicas do cenário nacional. Isso se faz recorrendo à linguagem humorística, irônica, caricata, sobretudo, quando se quer reprovar algum aspecto ou comportamento indevido dessas figuras públicas.

Outras vezes as mensagens têm o teor de familiaridade e intimidade entre os interlocutores:

"Olá ta triste comigo? Pesquisei uma estrela nesta noite, decidi dar a você pra que saiba o qnto é Brilhante e ESPECIAL pra mim”.

"O taxi está de volta trazendo a mim k sou seu amor, vou directo ao seu coração $\mathrm{k}$ Tb é meu. Não tenho hora pra voltar, um abco".

Mas também, pela ocasião de festas oficiais ou datas comemorativas os usuários trocam mensagens com pensamento crítico e dizeres educativos como estas que circularam no dia 04 de outubro de 2008, dia da paz:

\footnotetext{
3 Neste trabalho preservamos a grafia das mensagens como foram escritas originalmente. É possível ver alguns traços da linguagem digital, que não obedece às normas da linguagem formal e culta. É marcada por abreviaturas e novos códigos linguísticos, características da instantaneidade do processo comunicativo via redes digitais e condicionado por fatores espaciais das telas dos telefones móveis que não permitem apresentar textos longos.

4 Ainda não há dados exatos do número de usuários de celular em Moçambique, mas tudo indica que pela expansão da rede de telefonia móvel, que está alcançando regiões mais afastadas do país, até onde não existe energia elétrica, grande parte da população está optando por esse meio, pelas vantagens que oferece. As pessoas carregam as baterias de celular quando viajam para as vilas ou cidades ou então recarregam por meio de geradores que funcionam com combustíveis comuns como álcool e diesel.

5 Moçambique viveu 16 anos de guerra civil que envolveu as tropas do governo e do movimento da oposição RENAMO. A guerra cessou em 4 de outubro de 1992 com a Assinatura do Acordo Geral de Paz entre os dois beligerantes, em Roma. Por isso, esse dia é feriado nacional no país e conhecido como o Dia da Paz.
}

Rev. Estud. Comun., Curitiba, v. 10, n. 21, p. 29-36, jan./abr. 2009 
“A paz começa no coração e espalha-se pela aldeia, pelo distrito, pelo país e pelo mundo. Seja a pomba branca e espelhe a paz no mundo. "Feliz Dia da Paz!".

"O que é pra felicidade é feito de cuidados, e um cuidado é, por exemplo, a Paz!”.

"Paz na mente, Paz na alma, Paz no coração, Paz de espírito, Paz pra toda a vida...hje e sempre".

\section{Comunicação, participação e cidadania}

No ambiente da comunicação por celular percebemos que há maior interação entre os sujeitos interlocutores do discurso. As pessoas participam da produção e difusão de conteúdos de acordo com as modalidades que elas mesmas elegem como estratégias que lhes possam facilitar a interação com outros sujeitos individuais e coletivos. É nesse sentido que consideramos a comunicação comunitária como a que incentiva o indivíduo a participar da vida social.

Na concepção de Geaquinto (2002), participação e cidadania são conceitos intrínsecos. Essa concepção de cidadania é importante se pensarmos na inserção e na participação do indivíduo na definição dos destinos da vida da sociedade e pensando também nos deveres e responsabilidades que possui perante ela. Através da participação na definição da vida social, os indivíduos podem construir a cidadania e usufruir de seus direitos. Geaquinto explica que,

a cidadania emana da sua prática, do compromisso consciente do indivíduo ao atuar, ao assumir o papel de agente da transformação histórica e ocupar o seu espaço de forma objetiva dentro do universo político, econômico, cultural e social. A cidadania é que qualifica o cidadão e ela só se torna transparente e concreta através da ação. O indivíduo estanque, parado, é só indivíduo e não sujeito instituído de cidadania (GEAQUINTO, 2002, p. 27).

Através da troca de mensagens relacionadas a situações do quotidiano, as pessoas podem participar com suas ideias, e aprender a observar e a organizar seus argumentos e justificativas perante os fatos que acontecem na sociedade e isso pode ser facilitado não só pelo celular, mas também pela diversidade de veículos de comunicação presentes no país.

Exemplos disso são vários. Podemos observar essa mensagem difundida na rede da mCel, que faz referência à prisão do ex-ministro do Ministério do Interior, Almerino Manhenge e seus comparsas, acusados de desvio de dinheiro. No dia $1^{\circ}$ de outubro deste ano circulou a seguinte mensagem: "peço o seu número de conta bancária, tenho instruções de transferir um valor da conta do Manhenge para a sua. Não demore senão vão confiscar todo o taco". ${ }^{6}$

Uma contribuição importante que essas práticas comunicativas contemporâneas trazem é a possibilidade de abrir debates sobre assuntos de relevância social. A participação das pessoas nesses debates de maneira informal possibilita a construção do senso crítico e a capacidade de formar seu próprio ponto de vista diante dos fatos e essa dinâmica pode facultar condições para sua integração na sociedade. Nesse sentido, é válida a contribuição de Diaz (1982, p. 93) cuja abordagem reforça a necessidade de as pessoas aprenderem a usar os meios de comunicação. "Se os meios de comunicação são verdadeiras extensões do homem, por que não aprender a usá-los desde a infância em um sentido construtivo de autoexpressão e de construção de uma nova sociedade mais justa e solidária?"

Um dos aspectos importantes que se poderia desenvolver no meio rural moçambicano seria o de capacitar comunicadores locais para assegurarem a inserção e aprendizagem das pessoas, sobretudo, mais velhas, aquelas que não tiveram possibilidade de estudar e não conhecem as artimanhas das novas tecnologias de informação e comunicação. Poderiam também incentivar suas comunidades ao debate de temáticas atuais e influenciariam as comunidades a trabalharem para a mudança da realidade de exclusão em muitos aspectos como a social e digital a que se encontram relegados em relação aos meios urbanos.

Para que isso aconteça, Geaquinto (2002, p. 27) aponta a educação, em todas as suas formas, como um caminho importante para a construção da cidadania que, para o autor, "é uma via de mão dupla que traz o querer, o desejo,

\footnotetext{
${ }^{6} \mathrm{Na}$ gíria moçambicana a expressão taco é sinônimo de dinheiro.
} 
a reivindicação da concretização de um direito, e, por outro lado, enseja uma contrapartida, uma responsabilidade."

$\mathrm{Na}$ rede de celular, todas as pessoas têm possibilidades de expor suas ideias e opiniões sobre algum assunto que queiram compartilhar com os outros e dessa forma podem ampliar sua visão de mundo. Para incentivar essa postura nos cidadãos, sobretudo comuns, Moran (1998) defende a necessidade de se enfatizar na educação às habilidades que ajudem as pessoas a enfrentar cada nova etapa, o inesperado, e as ajude a desenvolver todas as potencialidades, equilibrando o sensorial, o emocional e o racional.

\section{CONSIDERAÇÕES FINAIS}

Nesse panorama da popularização do celular e do surgimento de novas práticas comunicativas apresentam-se alguns desafios quanto à produção e recepção de conteúdos midiáticos na atualidade, uma vez que Moçambique apresenta fortes desigualdades sociais e de acesso às tecnologias. Por um lado, grande parte da população ainda não tem acesso à água canalizada, à energia elétrica, e a condições necessárias à uma vida digna e saudável. Por outro, existe uma minoria que tem acesso às tecnologias de comunicação e informação e usufruem de atualizações constantes que lhes possibilita estarem ao mesmo patamar de cidadãos de países desenvolvidos. Como fazer com que as maiorias também tenham acesso a esses dispositivos e se apropriem de forma crítica e não alienante?

O conhecimento suficiente da realidade da maioria das comunidades rurais moçambicanas nos leva a avançar com algumas propostas de projectos exequíveis como o estabelecimento de centros comunitários para aprendizagem individual e coletiva do funcionamento de novos aparatos digitais e suas linguagens específicas. Esse processo possibilitaria às pessoas uma aprendizagem sobre o funcionamento dos meios digitais de forma consciente e crítica.

Através da conscientização sobre a própria potencialidade de serem possuidoras de saberes locais, as comunidades poderiam contribuir na produção de conteúdos simbólicos a serem difundidos na rede de telefonia móvel a que já têm acesso.

O ritmo de expansão da rede de telefonia indica que abrangerá, cada vez mais, boa parte da população rural, se comparado com o acesso a outros tipos de veículos de comunicação que dependem muito de outros condicionamentos como energia, estruturas físicas parainstalação, entre outros requisitos.

Esse panorama exige uma nova configuração da comunicação comunitária que já atua nesses espaços desde a independência do país, em 1975, e que tem desenvolvido sua programação em vista a atender os públicos do meio rural. Para isso, é imprescindível uma boa formação dos profissionais dessa área para que sejam capazes de responder aos desafios da atualidade.

Algumas questões, tanto no que tange à produção quanto à recepção de conteúdos midiáticos são pertinentes:

1) que as políticas públicas da comunicação possam enfatizar a inclusão digital para os cidadãos e que possibilitem a inclusão digital;

2) há necessidade de se pensar na criação de código de ética que assegure o respeito às individualidades e coletividades, mas um código que não seja destinado à censura e ao controle rígido de geração e difusão de conteúdos nas redes digitais, mas que permita o livre acesso à informação. Apesar dos conteúdos veiculados nesses tipos de mídias serem produzidos em espaços privados, são expostos em rede, que se configura como espaço público da era contemporânea;

3) é importante pensar também na formulação de leis que protejam os direitos autorais e penalizem ações deploráveis para aquilo a que as mídias se propõem: produzir conteúdos, difundir e armazená-los.

\section{REFERÊNCIAS}

BRAGA, J. L.; CALAZANS, M. R. Z. Comunicação e educação: questões delicadas na interface. São Paulo: Hacker, 2001.

DIAZ, B. J. E. O que é comunicação. São Paulo: Brasiliense, 1982.

GEAQUINTO, W. Cidadania, o direito de ser feliz: iguais e desiguais, até quando? 2. ed. São Paulo: Scortecci, 2002. 
LÉVY, P. Cibercultura. São Paulo: Ed. 34, 1999.

MORAN, J. M. Mudanças na comunicação pessoal: gerenciamento integrado da comunicação pessoal, social e tecnológica. São Paulo: Paulinas, 1998.

RODRIGUES, A. D. Comunicação e cultura: a experiência cultural na era da informação. Lisboa: Presença, 1994.

TRIVINHO, E. A dromocracia cibercultural: lógica da vida humana na civilização mediática avançada. São Paulo: Paulus, 2007.

WURMAN, R. S. Ansiedade de informação: como transformar informação em compreensão. São Paulo: Cultura, 1991.

Recebido: 12/10/2008

Received: 10/12/2008

Aprovado: 03/04/2009

Approved: 04/03/2009

Revisado: 26/10/2009

Reviewed: 10/26/2009 